\title{
Working Relationships Of IS Professionals And End Users: Testing Discrepancy Theory
}

Michael W. Boyd, (Email: michaelb@utm.edu), University of Tennessee, Martin Sid Glandon, (Email: sglandon@utep.edu), University of Texas, El Paso

TerryAnn Glandon, (Email: tglandon@utep.edu), University of Texas, El Paso

\begin{abstract}
Information systems (IS) services frequently fail to meet expectations of management and end users, in terms of budget, schedule, or requirements. Such failures may be attributed to the unique viewpoint and expectations of each set of stakeholders. A multidimensional measure of IS performance is used to examine the differences in expectations and perceptions of outcomes of IS professionals and two groups of end users - accountant end users and non-accountant end users. Results show that accountant end users have greater expectations than non-accountant end users, but similar expectations to IS professionals. Results show that performance was rated higher by IS professionals than either accountant-users or non-accountant users. Finally, discrepancy theory was tested with an ANOVA model to confirm that positive discrepancy (where outcomes exceed expectations) is associated with greater satisfaction for both stakeholder groups.
\end{abstract}

\section{INTRODUCTION}

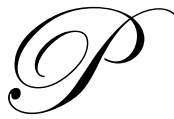

roviding quality information system (IS) services poses unique problems in many organizations. Linberg (1999) reports that over 31\% of all corporate software development projects are canceled prior to completion, almost 53\% exceed the budget by more than $200 \%$, and the average software project success rate is only about $16 \%$. Having no specific definition of "success" contributes to the reported high failure rate. Saarinen (1996) suggests that traditional investment analysis techniques and criteria are not sufficient to judge the success or failure of IS projects - such a narrow view limits the considerations to expectations, without taking into account perceptions of the final product. Instead, the evaluation process needs to be supplemented by "subjective judgment and surrogate measures." The current research adds to extant literature by comparing the expectations and perceptions of end users and IS professionals on IS performance, based on social perception and discrepancy theories.

Perceptional attitudes of people are an important aspect of creating and implementing IS services in an organization (DeLone and McLean 1992). Individuals' desires or wants, how they should be achieved, and the final outcome are all subjective and difficult to measure. Users are concerned with system characteristics and a working/service relationship with the provider personnel while IS personnel are more interested in the technical aspects and system quality (Graf and Misic 1994). The two primary stakeholders in the process, users and IS professionals, are naturally working with different perceptions of needs (Ives and Olson 1984; London 1995), with the final outcome often unsatisfactory to one or both groups.

A concerted effort to bring the stakeholders together through some type of evaluation process is imperative (Adelman 1992). The process must include a comprehensive set of measures that incorporate the views of both user and provider (Linberg 1999). Discrepancy theory (Locke and Latham 1990) provides the foundation of such a measuring tool. This theory simply states that individuals hold a set of expectations for a product, service or feature. The same individuals also have a perception as to how well that expectation is being met, with a positive discrepancy when the results are more than the expectation, and negative when those results are less than expected. 
Discrepancy theory may be able to explain the gap between the perceived products or services provided by IS personnel, compared to users' expectations. Expectations and outcome satisfaction for both stakeholder groups are measured using a multidimensional approach in the current study. Discovering differences between the perceptions of the different groups improve their working relationships, leading to better designed accounting information systems.

\section{LITERATURE REVIEW AND HYPOTHESIS DEVELOPMENT}

There has been much research on various applications of behaviorally based rating scales. In the early 1970s, such scales were initially adapted for research involving information systems (IS) analysts and programmers. Inherent in this endeavor was the development of lists of possible dimensions that could be explored and identified. Arvey and Hoyle (1974) underscored the use of proper statistical methods to determine the consistency and reliability of these multidimensional measures. In their 1982 study, Kaiser and Srinivasan added the IS end user to the realm of information systems research. They assessed the attitudinal differences of systems analysts and users to investigate the idea that differences between IS personnel and IS users could cause problems in the development and success of information systems projects. Kaiser and Srinivasan's study was an initial effort to demonstrate statistically that such differences do exist between stakeholders. Evaluation of those differences, however, required development of a set of metrics to capture the perspective of the end user as well as the IS professional's more technical view.

To develop the appropriate metrics, a greater understanding of social perceptions was required. Ross and Fletcher (1985) furthered this endeavor by explaining the cognitive process of studying and storing perceived facts about people and situations, and the way those individuals later draw on that perceived information to help them understand their present surroundings and situations. According to Ross and Fletcher, each individual's perceptions tend to be very specific, based on stored information. Thus, each individual is likely to have a unique perception of a situation due to past personal experiences.

However, these individual differences have not always been considered in prior research. Locke (1976) recognized that omitting these differences may not fully capture all aspects of perceptional variances. He argued that an individual's satisfaction with a particular outcome depends on what he or she originally wanted. The closer the match - the higher the level of satisfaction.

Behavioral researchers have empirically supported this claim. Results of various studies highlight an important distinction between discrepancy theory and other needs theories: desired aspects are not the same for all people, and satisfaction varies by individual values and personal perception of discrepancies. For example, Rice et al. (1989) found that a smaller discrepancy between an individual's desire for a specific outcome and the individual's perceived end outcome was associated with higher levels of satisfaction. Using job facets (e.g., pay rate, hours worked, customer contact) to measure satisfaction levels, the study demonstrated that two individuals in the same job had different responses toward the same outcome. These findings indicate that a person's satisfaction or dissatisfaction with a job facet is determined, in part, by discrepancies that result from a psychological comparison process that includes an individual's current experiences as compared to some personal standard of expectation.

The psychological comparison process can produce both positive and negative discrepancies. Positive discrepancies are experienced when the results are more than what was expected or desired. Accordingly, negative discrepancies are experienced when those results are less. As noted by Locke (1976), the effects of discrepancy on satisfaction depend on the individual's perception of the outcome. Rice et al. (1989) predicted job effort requirements (e.g., client/customer contact or hours worked per week) usually result in more satisfaction for individuals who want more customer contact or more hours. ${ }^{1}$ Assuming discrepancy theory holds when comparing the desires and outcome satisfaction of IS professionals and end users, a set of common metrics can be used to measure and interpret the differences in perceptions between these two groups.

\footnotetext{
${ }^{1}$ Some individuals may actually desire less customer contact (perhaps due to shyness) or fewer hours (a student with a heavy academic load). They are likely to experience less satisfaction even though the discrepancy is positive.
} 


\section{Hypotheses Development}

Social perception theory has been described as a cognitive process in which people notice, encode, store, and later retrieve information about other individuals (Jiang et al. 2000). During that process, they develop a unique schema to help them understand actions and events around them. Social perceptions include many sources of variation, including the individual's internal characteristics as well as external environments (Heneman et al. 1989). Consequently, it is likely that various groups of stakeholders will view metrics of success differently. In the context of IS professionals providing services to end users, a difference is expected between the perceptions of the two groups. In their study, Jiang et al. (2000) found that the ratings of IS personnel on factors relating to information systems services were higher (more important) than end users' ratings. They also found that perceptions of satisfaction with information system services provided were rated higher by IS professionals than by end users. Social perception theory and the results of the Jiang, et al. study leads to the following hypotheses, which test the overall expectation and outcome satisfaction differences between IS professionals and end users. They are stated in the alternative form as:

H1: The perceived expectations of information systems services will be rated higher by IS professionals than by end users.

H2: The perceived outcome satisfaction of information systems services will be rated higher by IS professionals than by end users.

End users employed in various functional areas of organizations may have different perceptions of ratings and performance of information system services, as suggested by Jiang et al. (2000). They encourage future research to determine whether those individuals working in certain functions possess different perceptions. Accountants have a unique educational experience with at least 20 percent of their academic career devoted to specialized and technical subjects. ${ }^{2}$ Therefore, accountants may have distinctive perceptions of ratings and performance, different from other, non-accountant, users. This question has not been addressed in prior research; for that reason, we examine it with the following hypotheses: H1a and Hypothesis H2a compare accountant-users' expectations and outcome satisfaction visà-vis non-accountant end users. Stated in the alternative form, they are:

H1a: There is a difference in perceived expectations of information systems services between accountant end users and non-accountant end users.

H2a: There is a difference in perceived outcome satisfaction of information systems services between accountant end users and non-accountant end users.

To further examine the differences between the two groups of end users and IS professionals in this sample, expectations and outcome satisfaction are compared between the user groups and the IS professionals who provided the services. Differences in expectations and outcome satisfaction between accountant-users and IS professionals are tested in Hypothesis $1 \mathrm{~b}$ and Hypothesis $2 \mathrm{~b}$. They are stated in the alternative form as:

H1b: There is a difference in perceived expectations of information systems services between IS professionals and accountant end users.

H2b: There is a difference in perceived outcome satisfaction of information systems services between IS professionals and accountant end users.

\footnotetext{
${ }^{2}$ A typical accounting education includes 24 semester hours of upper division accounting hours, which represents 20 percent of a bachelor's degree with a major in accounting.
} 
The expectations and outcome satisfaction of IS professionals vis-à-vis non-accountant end users are tested in the following hypotheses. Hypothesis $1 \mathrm{c}$ and Hypothesis $2 \mathrm{c}$ are stated in the alternative form as:

H1c: There is a difference in perceived expectations of information systems services between IS professionals and non-accountant end users.

H2c: There is a difference in perceived outcome satisfaction of information systems services between IS professionals and non-accountant end users.

Discrepancy theory suggests that the gap between each individual stakeholder's expectations and his or her perception of the resulting outcomes is related to overall perceived performance. Positive discrepancy results when a perceived outcome exceeds the stakeholder's wants/desires. Figure 1 presents a graphical view of positive and negative discrepancies.

Figure 1: Graphical view of Discrepancy Theory

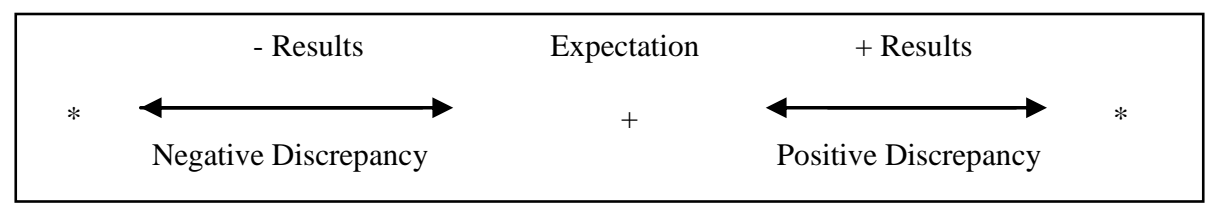

The average of the discrepancies for the six items that comprise the performance construct was used to create categories of positive and negative discrepancies. It was expected that the measure of user satisfaction with IS performance would be greater for the positive discrepancy category, similar to results from prior studies (Jiang et al. 2000; Baroudi and Orlikowski 1988; Bailey and Pearson 1983; Ives et al. 1983; and others). Stated in the alternative form, hypothesis 3 is presented to test this issue:

H3: A positive discrepancy between end user outcomes and desires/wants is positively associated with greater user satisfaction.

Career satisfaction has been used in prior studies as a measure of satisfaction for IS personnel (Tesch et al. 2003; Jiang et al. 2000; Igbaria et al. 1994a; Igbaria et al. 1994b; Greenhaus et al. 1990; and others). It is a function of progress toward meeting various career-related goals such as income, advancement, and learning new skills (Igbaria and Baroudi 1995; Greenhaus et al. 1990). For the current study, a positive discrepancy between the self-assessment of the IS professional's performance to his or her expectation of performance was expected to be positively related to career satisfaction. In a manner similar to that described above, categories of positive and negative discrepancies were created from the average discrepancies between the IS professionals' expectation of performance and actual performance. Hypothesis 4, stated in the alternative form, tests this research question:

H4: A positive discrepancy between the self-perception of the IS professional's performance and his or her expectation of performance is associated with greater career satisfaction.

\section{RESEARCH METHODOLOGY}

Data were collected from matched pairs of IS professionals and end users in the southern region of the U.S. IS professionals are described as those responsible for gathering information from the end users, solving problems, making system improvement proposals, training, and delivering and setting up finished system products. Two groups of end users participated in the study. One group consists of non-accountant end users, employed in various functions throughout the organizations. The members of the other group all work in the accounting function and are referred to as "accountant-users" for the remainder of the paper. 
Separating the end users into distinct groups was suggested by Jiang et al. (2000) to determine whether they had different perspectives on IS services. Accountants are frequent recipients of assistance from IS personnel, because of their extensive use of accounting information systems, as well as spreadsheet and database tools. Accountants also should be involved in the analysis of needs and design of systems because of their specialized knowledge of output, (e.g., compliance reports or GAAP for financial statements). Changes in corporate governance, including the passage of the Sarbanes-Oxley Act of 2002, have increased the need for accountants to understand and document the internal controls embedded in accounting information systems. This requires increased cooperation and coordination between IS personnel and accountants. It also increases the importance of studying the working relationship between these stakeholder groups.

A total of 440 survey instruments (220 matched pairs) were delivered personally to end users who were asked to complete a questionnaire and to request that a member of their organization's IS staff with whom they had worked complete the matching one. The importance of matched pairs was emphasized in addition to the requirement that each of these pairs had worked together in the recent past. Complete confidentiality was maintained for all participants; identification by the researchers was used solely to maintain the matched pair alignment. Company officials and/or supervisory personnel were not allowed to see the completed instruments. In 15 instances, one (of the pairs) of surveys was not completed; two of the accountant-users indicated they had not received IS services within the past year. Those 17 companies were eliminated from further analysis, resulting in a sample of 203 matched pairs (110 IS/accountant-user surveys and 93 IS/other-user surveys).

The questionnaires were identical for the end users and IS professionals except for certain demographics and the measurement of satisfaction (see Appendix). The end user was measured on outcome satisfaction through the use of a modified version of the instrument used by Jiang et al. (2000); the IS professional was measured on career satisfaction by using an instrument developed by Greenhaus et al. (1990)

Certain demographics of the respondents were requested on both versions of the questionnaire, such as gender, age, and industry. The IS survey also requested information regarding the respondent's position within the company. Demographics are presented in Table 1, illustrating that more men than women work in IS positions (male $=106$, female $=89$, blank $=8$ ) and that more women than men work in accounting positions (male $=48$, female $=57$, blank=5). Ages of participants ranged from 20 to 63 years, with an average age of 38 for IS personnel and nonaccountant end users. Accountants, on average, were slightly older, with a mean age of 43.

\section{Performance Construct}

Six multi-item measures were used to create the performance construct to evaluate 1) the user or IS staff's expectation of the IS services and 2) the satisfaction with the outcome of those services. Following are descriptions of the measures and support for their use in this research study:

Quality: The components of quality that are considered in the study are proper implementation of changes, understanding of applicable procedures, use of appropriate tools, recommendations for efficiency and effectiveness (DeLone and McLean 2003, 1992; Saarinen 1996; Bailey and Pearson 1983). Specific questions pertaining to technical quality were not included because end users may not be able to accurately judge that area of expertise.

Personal Qualities/Interpersonal Skills: The second category of performance is personal attributes. This construct concerns the interpersonal skills of IS personnel and investigates their efforts to listen and understand the wants and needs of end users. It also measures the respect that the IS professional affords the end user, along with their ability to build cooperative relationships and to enhance and generate dialog between themselves and end users (Lee et al. 1995; Green 1989; Bailey and Pearson 1983). Maintaining good relations with end users facilitates better working relationships, which can result in better performance on an organization-wide basis. 
Table 1: Descriptive Statistics.

\begin{tabular}{|c|c|c|c|c|c|c|}
\hline \multicolumn{7}{|c|}{ Participant Gender: } \\
\hline IS Personnel & \multicolumn{4}{|c|}{ Other End Users } & \multicolumn{2}{|c|}{ Accountant-Users } \\
\hline & 106 & \multicolumn{3}{|c|}{56} & & 48 \\
\hline $\mathrm{F}$ & 89 & \multicolumn{3}{|c|}{37} & & 57 \\
\hline Blank & 8 & \multicolumn{3}{|c|}{0} & & 5 \\
\hline Total & 203 & \multicolumn{3}{|c|}{93} & & 110 \\
\hline \multicolumn{7}{|l|}{ Participant Age: } \\
\hline IS Personnel & \multicolumn{4}{|c|}{ Other End Users } & \multicolumn{2}{|c|}{ Accountant-Users } \\
\hline $\mathrm{Max}$ & 63 & \multicolumn{3}{|c|}{61} & & 63 \\
\hline Win & 21 & \multicolumn{3}{|c|}{20} & & 22 \\
\hline Average & 38 & \multicolumn{3}{|c|}{38} & & 43 \\
\hline Blank & 6 & \multicolumn{3}{|c|}{2} & & 7 \\
\hline \multicolumn{4}{|c|}{ Position of IS personnel: } & \multicolumn{3}{|l|}{ Industry: } \\
\hline \multirow{8}{*}{$\begin{array}{l}\text { Technician } \\
\text { Systems analyst } \\
\text { Project leader } \\
\text { Nanager } \\
\text { Other } \\
\text { Total }\end{array}$} & & 85 & & Manufacturing & 60 & \\
\hline & & 32 & & Service & 54 & \\
\hline & & 19 & & Government & 26 & \\
\hline & & 60 & & Retai1/Wholesale & 24 & \\
\hline & & 7 & & Public Schools & 19 & \\
\hline & & 203 & & Banking & 16 & \\
\hline & & & & Other & 4 & \\
\hline & & & & Total & 203 & \\
\hline
\end{tabular}

Dependability: The third construct of the performance importance concerns dependability. It deals with IS personnel having met previous commitments, willingness to accept new assignments and follow through. It searches for the ideal situation of completion with eagerness to excel (Lee et al. 1995; Green 1989). Excitement and motivation are abstract concepts within an organization's culture that - once instilled - can become regenerating with little effort from upper levels of the management team. IS personnel gain a better understanding of the end users' expectations through cooperation and communication between the groups, improving dependability of IS services (Bailey and Pearson 1983).

Teamwork And Leadership: The fourth construct is designed to measure the leadership ability of the IS professional by encouraging pursuit of current project goals and other non-project related efforts. IS personnel should be able to coach, instruct, and support other IS personnel in the pursuit of quality and completion of the goals and objectives defined for IS services (Lee, et al 1995; Green 1989; Bailey and Pearson 1983). It is expected that the end user will be capable of recognizing these abilities in IS personnel.

Career-Related Activities: The fifth construct of the importance of performance deals with the career aspects of IS personnel. Tuttle and Harrell (2001) suggest that IS professionals are self-motivated and willing to pursue challenging goals. Such characteristics are likely to become apparent to the end user as the working relationship develops. The questions for this construct relate to the IS professional's pursuit of on-going training and education in order to stay current in the field. The second question deals with the IS professional being proactive, rather than passive, in developing new skills for career advancement. Finally, the respondent is asked about the IS personnel's initiative to participate in professional societies that support learning and currency in new and changing technology (Green 1989). According to Lee et al. (1995), end users expect IS personnel to maintain currency in new technology and improve skills/knowledge for existing technology.

General tasks: The general task factor looks for performance in response time, problem solution application, awareness of user needs, ability to resolve application and system problems, and the supply of knowledge and hardware for new technologies. All of these requirements are an integral part of the IS function and an attribute that 
the end user desires (Green 1989; Baroudi and Orlikowski 1988; Bailey and Pearson 1983). Timely response is an efficiency issue in any type of service and also increases satisfaction for end users. Anticipation of needs is a sign of good perception skills on the part of IS personnel, which also improves satisfaction for other stakeholders. Persistence in problem solving and training on various technological advances are examples of some of the performance measures desired by end users.

Respondents to the survey were asked to indicate the importance of each item on a five-point Likert-type scale, ranging from Not Important (1) to Very Important (5). Asking the respondent to indicate the importance of each performance category should reflect the level of expectation or desire associated with that performance. For example, if an end user marks "implement changes without errors or rework" as "very important," the end user has a high level of expectation for systems services to be completed correctly on the first attempt.

Similar measures have been validated in prior studies; nevertheless, to ensure that the data from our sample are a good fit to the model, a confirmatory factor analysis (CFA) was conducted. Goodness-of-fit indices considered were root mean square residual (RMR), Chi-square value/degrees of freedom, Bentler's comparative fit index (CFI), Bollen's nonnormed fit index (NNFI), normed fit index (NFI), goodness of fit index (GFI), and adjusted goodness-offit index (AGFI). The measures represent a strong fit for the model as presented along with the recommended levels in Table 2.

Table 2 also presents the performance construct items, their standardized loadings and associated $\mathrm{t}$-values. Convergent validity is demonstrated with all $\mathrm{t}$-values significant at the $\mathrm{p}=.05$ level. Internal reliability refers to the extent to which the survey instrument is free from measurement error and can be assessed using Cronbach's alpha. As illustrated in Table 2, Cronbach's alpha for the six items range from .68 to .82., which are acceptable levels of internal reliability.

Discriminant validity was evaluated by examining whether the confidence intervals of the correlations among the latent variables includes the value of 1.0. With the current data, none of the confidence intervals included this benchmark value and adequate discriminant validity is assumed among the model constructs.

\section{Career Satisfaction Construct}

Career satisfaction of IS professionals was measured by an instrument developed by Greenhaus et al. (1990). The construct used to measure IS professionals' satisfaction with their careers consists of five questions that deal with career success; meeting overall career goals, income goals, advancement goals, and goals set for learning new skills. This instrument has been widely used in other studies reported in the IS literature (c. f. Tesch et al. 2003; Igbaria et al. 1994a; Igbaria et al. 1994b). Respondents were asked to indicate their agreement or disagreement with each item on a five-point Likert-type scale that ranged from Strongly Disagree (1) to Strongly Agree (5).

Table 3 presents the items, their standardized loadings and associated t-values. The construct demonstrates convergent reliability, with all t-values significant at the $\mathrm{p}=.05$ level. Cronbach's alpha for the IS career satisfaction construct is .89 , which is an acceptable level of internal reliability. A confirmatory factor analysis was conducted using the goodness of fit indices described earlier. The results, reported in Table 3, indicate a good fit of the measurement model when compared to the recommended values. 
Table 2: Properties of Performance Construct - Convergent Validity and Reliability.

\begin{tabular}{|c|c|c|c|c|c|}
\hline Item & & Loadings & t-value & & $\begin{array}{c}\text { Cronbach } \\
\text { Alpha }\end{array}$ \\
\hline \multicolumn{6}{|l|}{ Quality: } \\
\hline Implement changes without errors or rework & & 0.43 & 12.40 & $*$ & 0.68 \\
\hline Understand and follow applicable procedures and work instructions. & & 0.55 & 10.52 & $*$ & \\
\hline Use tools and standards properly and consistently & & 0.75 & 4.29 & $*$ & \\
\hline Recommend and pursue ways to be more effective and efficient & & 0.32 & 12.77 & $*$ & \\
\hline \multicolumn{6}{|l|}{ Personal Quality/Interpersonal Skills: } \\
\hline Make an effort to listen to and understand the users & & 0.69 & 9.19 & $*$ & 0.82 \\
\hline $\begin{array}{l}\text { Show respect; build cooperative relationships; facilitate dialog } \\
\text { among people }\end{array}$ & & 0.68 & 8.95 & * & \\
\hline Make ideas understood; answer questions in a way that users understand & & 0.67 & 9.15 & $*$ & \\
\hline \multicolumn{6}{|l|}{ Dependability: } \\
\hline Meet commitments & & 0.64 & 7.38 & $*$ & 0.82 \\
\hline Willing and able to accept new assignments & & 0.52 & 10.61 & $*$ & \\
\hline Follow through on general services or special projects & & 0.59 & 9.32 & $*$ & \\
\hline \multicolumn{6}{|l|}{ Teamwork and Leadership: } \\
\hline Contribute actively to project and non-project related efforts & & 0.65 & 10.36 & $*$ & 0.81 \\
\hline Lead a team toward its stated objectives & & 0.71 & 8.61 & $*$ & \\
\hline Coach, instruct, and/or support other IS personnel & & 0.69 & 9.13 & $*$ & \\
\hline \multicolumn{6}{|l|}{ Career-related Activities: } \\
\hline Pursue necessary training and education to remain up-to-date & & 0.67 & 9.85 & $*$ & 0.79 \\
\hline Seek opportunities to develop skills for future advancement & & 0.82 & 4.28 & $*$ & \\
\hline $\begin{array}{l}\text { Participation in professional societies to help stay current in new } \\
\text { and changing technologies }\end{array}$ & & 0.59 & 11.60 & $*$ & \\
\hline \multicolumn{6}{|l|}{ General Tasks: } \\
\hline Respond in a timely fashion & & 0.57 & 11.43 & $*$ & 0.80 \\
\hline Apply preventative or permanent solutions to problems & & 0.49 & 12.45 & $*$ & \\
\hline Anticipate user's needs; giving high priority to user satisfaction & & 0.60 & 10.64 & $*$ & \\
\hline Stick with user's problem until it is resolved & & 0.60 & 10.70 & $*$ & \\
\hline $\begin{array}{l}\text { Keep users informed about information technologies related } \\
\text { to the user's job (e.g. hardware, software, books, and manuals) } \\
\text { * indicates significance at } p<0.05 \text { level }\end{array}$ & & 0.54 & 10.78 & $*$ & \\
\hline CFA Fit Indices: & & \multicolumn{4}{|c|}{ Suggested Minimum Indices: } \\
\hline 1. Root Mean Square (RMR): & 0.02 & & RMR & & $<=0.05$ \\
\hline 2. Chi-squared/ d.f. ratio: & 1.70 & & Ratio & & $<5$ \\
\hline 3. Comparative Fit Index (CFI): & 0.98 & & CFI & & $>=0.90$ \\
\hline 4. Bollen Nonnormed Fit Index (NNFI): & 0.98 & & NNFI & & $>=0.90$ \\
\hline 5. Normed Fit Index (NFI): & 0.95 & & NFI & & $>=0.90$ \\
\hline 6. Goodness of Fit Index (GFI): & 0.96 & & GFI & & $>=0.90$ \\
\hline 7. Adjusted Goodness of Fit Index (AGFI): & 0.91 & & AGFI & & $>=0.90$ \\
\hline
\end{tabular}


Table 3: Properties of Career Satisfaction Construct - Convergent Validity and Reliability.

\begin{tabular}{|c|c|c|c|c|c|}
\hline Item & & Loadings & t-value & & $\begin{array}{c}\text { Cronbach } \\
\text { Alpha }\end{array}$ \\
\hline I am satisfied with the success I have achieved in my career & & 0.83 & 7.83 & $*$ & 0.89 \\
\hline $\begin{array}{l}\text { I am satisfied with the progress I have made toward meeting } \\
\text { my overall career goals }\end{array}$ & & 0.90 & 5.90 & $*$ & \\
\hline I am satisfied with the progress I have made toward meeting & & & & & \\
\hline my goals for income & & 0.67 & 9.23 & $*$ & \\
\hline I am satisfied with the progress I have made toward meeting & & 088 & 738 & $*$ & \\
\hline I am satisfied with the progress I have made toward meeting & & & & & \\
\hline my goals for the development of new skills & & 0.67 & 9.20 & $*$ & \\
\hline$*$ indicates significance at $\mathrm{p}<0.05$ & & & & & \\
\hline CFA Fit Indices: & & \multicolumn{4}{|c|}{ Suggested Minimum Indices: } \\
\hline 1. Root Mean Square (RMR): & 0.02 & & RMR & & $<=0.05$ \\
\hline 2. Chi-squared/ d.f. ratio: & 2.44 & & Ratio & & $<5$ \\
\hline 3. Comparative Fit Index (CFI): & 0.98 & & CFI & & $>=0.90$ \\
\hline 4. Bollen Nonnormed Fit Index (NNFI): & 0.98 & & NNFI & & $>=0.90$ \\
\hline 5. Normed Fit Index (NFI): & 0.98 & & NFI & & $>=0.90$ \\
\hline 6. Goodness of Fit Index (GFI): & 0.97 & & GFI & & $>=0.90$ \\
\hline 7. Adjusted Goodness of Fit Index (AGFI): & 0.93 & & AGFI & & $>=0.90$ \\
\hline
\end{tabular}

\section{TESTING DISCREPANCY}

The major difficulty in measuring a gap, or discrepancy, is the accuracy of the measure of two different perspectives on the same issue (Headley and Choi 1992). The current research formulates methods for accurately measuring this gap from two different stakeholders by administering identical questionnaires to IS professionals and end users. T-tests were used to test for differences in their evaluation of expectations (Hypothesis 1) and the difference in their perceptions on the delivery of service (Hypothesis 2) between all end users and the IS personnel in the sample.

An ANOVA model was used to test discrepancy theory. Based on prior studies, (e.g., Jiang et al. 2000; Locke and Latham 1990; Rice, et al. 1989), it was expected that the mean responses for the positive gaps (outcome > expectation) would be higher than the means for the negative gaps (outcome < expectation). In the current study, the positive discrepancy experienced by end users was expected to be associated with greater user satisfaction (H3) and the positive discrepancy experienced by information systems professionals was expected to be associated with greater career satisfaction (H4).

\section{RESULTS}

T-tests were conducted to establish that end users and IS professionals start with differing expectations of information systems services and differing perceptions of outcome of those services. As presented in Panel A of Table 4, the IS professionals had higher expectations of work to be performed (mean $=4.42 . \mathrm{SD}=.36$ ) than the end users $($ mean $=4.31, \mathrm{SD}=.47)$. The IS professionals also assessed their own performance higher (mean $=4.23, \mathrm{SD}=$ .51 ) than end users (mean $=4.09, \mathrm{SD}=.72)$. In both instances, the t-tests indicate reliable differences at $\mathrm{p}<.05$, supporting Hypothesis 1 and Hypothesis 2. The results are consistent with those of the Jiang et al. (2000) study on IS personnel and end users.

Panel B of Table 4 presents the results of hypotheses H1a-H1c and H2a-H2c. T-tests were used to compare the means of expectations between the stakeholder groups. It was expected that each group would have different expectations. The data partially support these hypotheses: H1a is supported, with a mean $=4.42(\mathrm{SD}=.43)$ for 
accountant-users and a mean of $4.17(\mathrm{SD}=.48)$ for non-accountant users $(\mathrm{p}<.05)$. Hypothesis H1b, which tested for differences of expectations between accountant-users and the IS personnel with whom they work, is not supported. Expectations of the two groups were virtually the same: the mean of accountant-users was 4.42 (SD $=.43$ ) and the IS personnel mean was $4.44(\mathrm{SD}=.35)(\mathrm{t}$-value $=.31)$. Finally, IS personnel had higher performance expectations than those of non-accountant users: IS personnel's mean $=4.39,(\mathrm{SD}=.36)$, while the mean of non-accountant users $=4.17$ $(\mathrm{SD}=.48)(\mathrm{p}<0.05)$, supporting H1c.

The levels of outcome satisfaction between the stakeholder groups were tested with Hypotheses $2 \mathrm{a}, 2 \mathrm{~b}$, and 2c. It was anticipated that accountant-users would have different satisfaction levels than non-accountant users. However, their responses were virtually the same, with means $=4.04(\mathrm{SD}=.62)$ for accountant-users and $4.08(\mathrm{SD}=$ .77) for non-accountant users. Differences were found in outcome satisfaction between IS personnel - mean of 4.19 $(\mathrm{SD}=.51)-$ and accountant-users' mean of $4.04(\mathrm{SD}=.62)(\mathrm{H} 2 \mathrm{~b}, \mathrm{p}<0.05)$. Considering the outcome satisfaction differences between IS professionals and non-accountant users (H2c), IS personnel had a higher self-assessment of their performance $($ mean $=4.28, \mathrm{SD}=.51$; the mean of non-accountant users $=4.08, \mathrm{SD}=.77)(\mathrm{p}<0.05)$.

Table 4: Differences Between Expectations and Outcome Satisfaction of Stakeholders.

\begin{tabular}{|c|c|c|c|c|c|c|}
\hline$\underline{\text { Panel } \mathrm{A}-\mathrm{H} 1 \text { and } \mathrm{H} 2}$ & & & $\begin{array}{c}\text { All } \\
\text { End Users } \\
\text { Mean (S.D.) } \\
\end{array}$ & & $\begin{array}{c}\text { All } \\
\text { IS Personnel } \\
\text { Mean (S.D.) } \\
\end{array}$ & \\
\hline Expectations & & & $4.31(0.47)$ & $*$ & $4.42(0.36)$ & * \\
\hline Outcome Satisfaction & & & $4.09(0.72)$ & * & $4.23(0.51)$ & * \\
\hline Panel B - H1a, b, c and H2a, b, c & $\begin{array}{l}\text { Accountant } \\
\text { Users } \\
\text { Mean (S.D.) } \\
\end{array}$ & & $\begin{array}{c}\text { Non-Accountant } \\
\text { Users } \\
\text { Mean (S.D.) } \\
\end{array}$ & & $\begin{array}{l}\text { IS Personnel } \\
\text { Mean (S.D.) }\end{array}$ & \\
\hline \multicolumn{7}{|l|}{ Expectations: } \\
\hline $\mathrm{H} 1 \mathrm{a}$ & $4.42(0.43)$ & $*$ & $4.17(0.48)$ & $*$ & & \\
\hline $\mathrm{H} 1 \mathrm{~b}$ & $4.42(0.43)$ & & & & $4.44(0.35)$ & \\
\hline $\mathrm{H} 1 \mathrm{c}$ & & & $4.17(0.48)$ & $*$ & $4.39(0.36)$ & * \\
\hline \multicolumn{7}{|l|}{ Outcome Satisfaction: } \\
\hline $\mathrm{H} 2 \mathrm{a}$ & $4.04(0.62)$ & & $4.08(0.77)$ & & & \\
\hline $\mathrm{H} 2 \mathrm{~b}$ & $4.04(0.62)$ & $*$ & & & $4.19(0.51)$ & $*$ \\
\hline $\mathrm{H} 2 \mathrm{c}$ & & & $4.08(0.77)$ & $*$ & $4.28(0.51)$ & $*$ \\
\hline
\end{tabular}

\section{Discrepancy Theory Results}

In discrepancy theory, a positive gap results when the outcome exceeds the expectation of that outcome. Accordingly, a negative gap exists when the outcome does not meet the original expectations. In the current study, the discrepancy measure was calculated by using the average of the discrepancies for the six items that comprise the performance construct. An ANOVA model was used to test discrepancy theory, with categories of the ANOVA based on whether the discrepancy was positive or negative.

For the end users, outcomes are considered in terms of user satisfaction, with expectations used as the basis for comparison. The satisfaction end users derive from the IS services they are provided depends on their perception of the quality of delivery, interpersonal skills of the IS professional, and so on. End users with positive discrepancy (expectation < outcome) experience greater user satisfaction than those with negative discrepancy (expectation > outcome). The ANOVA model employs end user satisfaction with IS services as the dependent variable and the discrepancy gap as the independent variable in Hypothesis 3. Discrepancy theory holds in the current study with 
respect to user satisfaction: 70 end users experienced a positive gap $($ mean $=4.61)$ while 128 end users experienced a negative gap, with a mean of $4.36(\mathrm{p}=0.01)$.

Testing Hypothesis 4 involved a similar process, using IS personnel's career satisfaction as the dependent variable and the discrepancy gap as the independent variable. Discrepancy theory also held in this study with regard to career satisfaction. The mean for the positive gap in career satisfaction for IS professionals $(n=77)$ is 4.60 and the mean for the negative gap is $4.44(\mathrm{n}=121 ; \mathrm{p}=0.04)$.

Table 5: Results for H3 and H4 - ANOVA Analysis.

\begin{tabular}{|l|c|c|c|}
\hline & $\begin{array}{c}\text { Expectations } \\
\text { < Outcome }\end{array}$ & $\begin{array}{c}\text { Expectations } \\
>\text { Outcome }\end{array}$ & p-value \\
\hline User Satisfaction & $\begin{array}{c}4.61 \\
(\mathrm{n}=70)\end{array}$ & $\begin{array}{c}4.36 \\
(\mathrm{n}=128)\end{array}$ & 0.01 \\
\hline Career Satisfaction & $\begin{array}{c}4.60 \\
(\mathrm{n}=77)\end{array}$ & $\begin{array}{c}4.44 \\
(\mathrm{n}=121)\end{array}$ & 0.04 \\
\hline
\end{tabular}

$\mathrm{n}=198$

\section{Additional Analyses}

Further statistical analyses were conducted on possible perceptional differences due to age and to gender. To test for differences in age, the mean age of 41 was used to split the data into two groups. One group consisted of 226 individuals, age 20 to 41 ; the other group was made up of 165 individuals age 42 and older; fifteen respondents left that question blank. There was virtually no difference in perceptions of expectations or outcome satisfaction due to age.

Next, the data were analyzed for differences in perceptions due to gender. There was no distinction between all males and females in either expectations or outcome satisfaction, nor was there a difference in satisfaction between end users. However, there were differences in male and female expectations within the user groups. First, female accountant-users had greater expectations than any non-accountant users (Mean $=4.47, \mathrm{SD}=.44$ ), although male accountant-user responses were only slightly lower (Mean $=4.42, \mathrm{SD}=.50$; no significant difference). Female accountant-users' responses (Mean $=4.47$ ) also were higher than other female users (Mean $=4.34, \mathrm{SD}=.37, \mathrm{p}<$ $0.05)$. Finally, male accountant-user expectations (Mean $=4.42$ ) were greater than other male users at Mean $=4.22$ $(\mathrm{SD}=.50 ; \mathrm{p}<0.001)$.

\section{DISCUSSION}

Past research in organizational behavior and social perception theories predicted that differences exist between individual expectations and perceived satisfaction with outcomes, as well as differences between groups. Ross and Fletcher (1985) explain this cognitive process of studying and storing perceived facts about people and situations and how they draw on that information at later times to help them understand their present surroundings and situations. The situations and past experiences tend to be very individualized to the person who has stored that information; thus, each person could perceive similar situations differently because of his or her past experiences. For the current study, results indicate that at least some perceptional differences exist between IS professionals and all end users; that is, the groups ranked both expectations and outcomes differently. It is not unexpected that end users "graded" IS services lower than IS personnel's assessment of their own performance. For example, the IS professional would have a clearer understanding of potential impediments encountered in delivering services, such as incompatibility of existing hardware, platforms, and applications. Therefore, their self-evaluation may include an adjustment that considers such obstacles. 
Management research has suggested that there are risks associated with self-appraisals that are higher than the evaluations by co-workers. For example, McCall and Lombardo (1983) suggest that inflated self-evaluations can be associated with career derailment. Moreover, McCauley and Lombardo (1990) found managers were more likely to be promoted when their self-assessments were consistent with those of their coworkers and customers. A longitudinal study of IS professionals may provide additional insight to determine whether similar experiences occur in careers in information systems.

As with the results of the Jiang, et al. (2000) study, responses of end users were lower than the responses of IS professionals for expectations of information system services. Perhaps end users considered prior IS services and had experienced less-than-satisfactory results, and therefore lowered their expectations. In future studies it may be helpful to establish the length of time, or number of occasions, that the IS professionals and end users worked together to determine a possible effect on perceptions of expectations, performance, or both.

Individuals not only have personal perceptions of expectations and performance, but they also possess a certain communication style. In future research it may also be beneficial to measure the communication styles of the stakeholders, using communicator style measures such as those developed by Norton and Miller (1975).

Accountant-users had similar expectations as IS personnel. A case could be made that the education and training of accountants and IS professionals include similar (although not identical) technical aspects, making these two groups more closely aligned. This argument could be strengthened in future studies by requesting the level of education on the questionnaire. Nonetheless, both accountant-users and IS personnel had higher expectations than the non-accountant users, adding credence to this supposition.

Unexpectedly, there was virtually no difference in levels of satisfaction between the different user groups. Accountant-users had higher expectations than non-accountant users, but were not less satisfied when those expectations were not met. Perhaps accountants, by their very nature, have high expectations but are not necessarily disappointed when those expectations are not met. Could this mean accountants are more realistic or perhaps simply more cynical about efforts of their co-workers?

Future researchers may wish to collect more demographic data on the two end user groups. Respondents in management positions may have different perceptions than those in administrative or staff-level positions. For example in the accounting function, it may be informative to determine whether internal auditors, staff accountants, tax accountants, controllers, etc. view expectations and outcome satisfaction differently.

This research extends information systems literature in that it examines differences in expectations and performance of IS services from the perspective of IS professionals and end users. Furthermore, it contributes to accounting literature by gathering perspectives from individuals who are employed in an accounting function.

\section{REFERENCES}

1. Adelman, L. 1992. Evaluating Decision Support and Expert Systems. New York, NY: John Wiley \& Sons.

2. Arvey, R. D. and Hoyle, J. C., 1974. "A Guttman approach to the development of behaviorally based rating scales for systems analysts and programmer/analysts". Journal of Applied Psychology (February): 61-68.

3. Bailey, J. E. and Pearson, S. W. , 1983. "Development of a tool for measuring and analyzing computer user satisfaction". Management Science (May): 530-545.

4. Baroudi, J. J. and Orlikowski, W. J., 1988. "A short form measure of user information satisfaction: A psychometric evaluation and notes on use". Journal of Management Information Systems (Spring): 44-59.

5. DeLone, W. H. and McLean, E. R., 2003. "The DeLone and McLean model of information systems success: A ten-year update". Journal of Management Information Systems (Spring): 9-30.

6. DeLone, W. H. and McLean, E. R., 1992. "Information systems success: The quest for the dependent variable". Information Systems Research (March): 60-94.

7. Graf, D. and Misic, M., 1994." The interpersonal environment of the systems analyst". Journal of Systems Management (September): 15-23. 
8. Green, G. I., “1989. Perceived importance of system analysts' job skills, roles, and non-salary incentives”. MIS Quarterly (June): 115-133.

9. Greenhaus, J. H., Parasuraman, S. and Wormley, W. M., 1990. "Effects of race on organizational experience, job performance evaluation, and career outcomes". Academy of Management Journal (March): 64-96.

10. Headley, D. E. and Choi, B., 1992. "Achieving service quality through gap analysis and a basic statistical approach". The Journal of Services Marketing (Winter): 5-14.

11. Heneman, R. L., Greenberger, D. B., and Anonyuo, C., 1989. "Attributions and exchanges: The effects of interpersonal factors on the diagnosis of employee performance". Academy of Management Journal (June): 466-476.

12. Igbaria, M. and Baroudi, J. J., 1995. "The impact of job performance evaluations on career advancement prospects: An examination of gender differences in the IS workplace". MIS Quarterly (March): 107-123.

13. Igbaria, M., Baroudi, J. J., Meredith, G., and Smith, D. C., 1994a. "Predictors of intentions of IS professionals to stay with the organization in South Africa". Journal of Strategic Management Information Systems (December): 245-256.

14. Igbaria, M., Baroudi, J. J., Meredith, G., and Smith, D. C., S. Parasuraman, and M. K. Badawy, 1994b. "Work experiences, job involvement, and quality of work life among information systems personnel". MIS Quarterly (June): 175-201.

15. Ives, B. and Olson, M. H., 1984. "User Involvement and MIS success: A review of research". Management Science (May): 19-25.

16. Ives, B., Olson, M. H., and Baroudi, J. J., 1983. "The measurement of user information satisfaction". Communications of the ACM (October): 785-793.

17. Jiang, J. J., Sobol, M. G., and Klein, G., 2000. "Performance ratings and importance of performance measures for is staff: The different perceptions of IS users and IS staff". IEEE Transactions on Engineering Management (November): 424-434.

18. Kaiser, K. and Srinivasan, A., 1982. "User-analyst differences: An empirical investigation of attitudes related to systems development". Academy of Management Journal (September): 630-646.

19. Lee, M. S., Trauth, E. M., and Farwell, D., 1995. "Critical skills and knowledge requirements of IS professionals: A joint academic/industry investigation”. MIS Quarterly (September): 313-340.

20. Linberg, K. R., 1999. "Software developer perceptions about software project failure: A case study". The Journal of Systems and Software 49: 177-192.

21. Locke, E. A., 1976. "The nature and causes of job satisfaction". In Dunnett, E. (ed.), Handbook of Industrial and Organizational Psychology. Chicago, IL: Rand McNally: 1297-1350.

22. Locke, E. A. and Latham, G. P., 1990. A theory of goal setting and task performance. New York, NY: Prentice Hall.

23. London, M., 1995. Self and interpersonal insight: How people learn about themselves and others in organizations. New York, NY: Oxford University Press.

24. McCall, M. W. and Lombardo, M. M., 1983. "Off the track: Why and how successful executives get derailed". Technical Rep. 21, Greensboro, NC: Center for Creative Leadership.

25. McCauley, C. and Lombardo, M. M., 1990. "Benchmarks: An instrument for diagnosing managerial strengths and weaknesses". Measures of Leadership, Clark, K. E. and Clark, M. B. (Eds.) West Orange, NJ: Leadership Library of America. 535-545.

26. Norton, R. and Miller, L., 1975. "Dyadic perception of communicator style". Human Communication Research 2: 50-67.

27. Rice, R. W., McFarlin, D. B., and Bennett, D. E., 1989. "Standards of comparison and job satisfaction". Journal of Applied Psychology (August): 591-598.

28. Ross, M. and Fletcher, G. J. O., 1985. "Attribution and social perception". In Lindzey, G., and Aronson, E. (Eds.) Handbook of Social Psychology $2^{\text {nd }}$ ed., New York, NY: Random House.

29. Saarinen, T., 1996. "An expanded instrument for evaluating information system success". Information \& Management (November): 103-118.

30. Tesch, D., Jiang, J. J., and Klein, G., 2003. "The impact of information system personnel skill discrepancies on stakeholder satisfaction”. Decision Sciences (Winter): 107-129. 
31. Tuttle, B. M. and Harrell, A. M., 2001. "The impact of unit goal priorities, economic incentives, and interim feedback on the planned effort of information systems professionals". Journal of Information Systems. (Fall): 81-98.

\section{NOTES}

